\title{
Erratum to: Impact of red blood cells count on the relationship between high density lipoproteins and the prevalence and extent of coronary artery disease: a single centre study
}

\author{
Alon Schaffer ${ }^{1} \cdot$ Monica Verdoia $^{1} \cdot$ Ettore Cassetti $^{1} \cdot$ Lucia Barbieri $^{1}$ \\ Pasquale Perrone-Filardi ${ }^{2} \cdot$ Paolo Marino $^{1} \cdot$ Giuseppe De Luca $^{1}$
}

Published online: 24 March 2015

(C) Springer Science+Business Media New York 2015

\section{Erratum to: J Thromb Thrombolysis}

DOI 10.1007/s11239-015-1174-x

The original version of the article has been published with the incorrect article title. The correct article title is given in this erratum.

The online version of the original article can be found under doi:10.1007/s11239-015-1174-x.

Giuseppe De Luca

giuseppe.deluca@med.unipmn.it

1 Division of Cardiology, Azienda Ospedaliera-Universitaria "Maggiore della Carità", Eastern Piedmont University, C.so Mazzini, 18, 28100 Novara, Italy

2 Department of Advanced Biomedical Sciences, University of Naples Federico II, Naples, Italy 